\title{
COMMENTARY
}

\section{Medical Social Service Officers and their contribution in COVID-19 Pandemic}

\section{Anant Gupta ${ }^{1}$, Jitender Sodhi ${ }^{2}$, B. R. Shekhar ${ }^{3}$, D. K. Sharma ${ }^{4}$}

${ }^{1}$ Senior Resident, Department of Hospital Administration, All India Institute of Medical Sciences, New Delhi110029; ${ }^{2}$ Assistant Professor, Department of Hospital Administration, All India Institute of Medical Sciences, New Delhi-110029; ${ }^{3}$ Chief Medical Social Officer, All India Institute of Medical Sciences, New Delhi-110029; ${ }^{4}$ Medical Superintendent, All India Institute of Medical Sciences, New Delhi-110029.

\begin{tabular}{|c|c|c|c|c|c|c|c|c|}
\hline Abstract & Introduction & Methodology & Results & Conclusion & References & Citation & \multicolumn{2}{|c|}{ Tables / Figures } \\
\hline \multicolumn{9}{|c|}{ Corresponding Author } \\
\hline \multicolumn{8}{|c|}{$\begin{array}{l}\text { Jitender Sodhi, Room no. 8, Department of Hospital Administration, All India Institute of Medical } \\
\text { Sciences, New Delhi - 110029, India } \\
\text { E Mail ID: jitendrasodhi27@gmail.com }\end{array}$} & 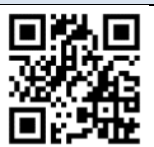 \\
\hline
\end{tabular}

\section{Citation}

Gupta A, Sodhi J, Shekhar BR, Sharma DK. Medical Social Service Officers and their contribution in COVID-19 Pandemic. Indian J Comm Health. 2020;32(3):610-612.

Source of Funding: Nil Conflict of Interest: None declared

\section{Article Cycle}

Received: 30/07/2020; Revision: 13/08/2020; Accepted: 28/08/2020; Published: 30/09/2020

This work is licensed under a Creative Commons Attribution 4.0 International License.

\section{Abstract}

Social workers perform diverse roles in a hospital setting. They constitute an important workforce extending help to patients for their varied needs. In the current pandemic as well, team of social workers worked round the clock to arrange for the resources and facilitated important hospital functions. They are the "unsung heroes" amongst the front line warriors who sometimes even do not get their due recognition.

\section{Introduction}

Social workers over the years have contributed immensely for promotion of human health and well being in the society. Social workers perform multitude of functions in a hospital, such as psychosocial assessment, education, discharge planning, advocacy, counselling, case conferencing, crisis intervention and community outreach 1 . The role of the medical social worker is to work with patients, their families, and members of the health care team to address their emotional and social issues that impact health and wellbeing 2 . Various studies have illustrated that medical social workers are valuable asset to a hospital, as they assist in acute and rehabilitative interventions after medical diagnosis 3. Coronavirus disease caused by severe acute respiratory syndrome coronavirus 2 (SARSCoV-2) was first reported in China in late December, 2019 and evolved into a global pandemic. As of 2 nd July 2020, COVID-19 has been confirmed in more than 10.7 million individuals in 188 countries and regions, with an overall mortality rate of more than $5 \%$ 4. With COVID-19 pandemic, the manufacturing industry came to a standstill which led to the acute shortages of various essential supplies everywhere. As the infection is transmitted by droplets, there was an increased demand of personal protective gear especially face masks, hand-sanitizers, tyvek suits, goggles and face shields. The COVID-19 outbreak resulted in the close down of outpatient services and elective surgeries with in-patient admissions happening only through the route of emergency which escalated its workload many times. The challenge of patient co-ordination and their transfers to COVID units, availability of face masks and other PPE gear, transfer of dead bodies, grief counselling, help to poor patients and various other such roles were performed by a dedicated unit of our Medical Social Service Officers.

\section{Structure of the unit}

The Medical Social Welfare Unit (MSSO) came into being in 1960 in AlIMS, New Delhi when the first Medical Social Worker was appointed on the strength of its main hospital. The MSSO Unit works under the supervision and administrative control of Medical Superintendent office from its inception. It 
has on its strength, 12 Medical Social Service Officers

(MSSOs) who cater to the requirements of patients from out-patients and in-patients of around twenty odd clinical departments of the main hospital. In addition to the team of MSSOs, around 20 Part-time Social Guides (PTSG) also work under the unit for facilitation of patient care services and guidance.

The Medical Social Services continue to serve as an important pillar of support to the patients, both poor and destitute coming to AlIMS by extending them the much needed social, psychological and financial support. Unfortunately, this cadre of officers never got their due recognition as they play their role behind the curtain. The key roles performed by MSSO are described in [Table 1].

\section{Contribution of MSSOs during COVID-19 pandemic}

AlIMS hospital was designated as one of the COVID19 hospitals by Ministry of Health and Family welfare, Govt of India. It had its own requirements, challenges and indeed the opportunities to improve its system \& processes. Keeping these in consideration, a team of $06 \mathrm{MSSO}$ were posted round the clock in the emergency department to help, guide and facilitate for specials requirements of the patients. Patients who had their planned surgeries scheduled and were in Delhi, the MSSO helped them in getting accommodation to stay in the Vishram Sadans of AllMS. The team of MSSOs counselled the inmates of our Vishram Sadans (both patients and their attendants) on the aspects of hand hygiene, respiratory etiquettes and social distancing. The time period of first lock down w.e.f 24th March 2020 to 14th April 2020 was the most challenging one as it adversely affected the various supply chains of crucial items. At this juncture, the infantry of our MSSOs took the lead. They tapped the philanthropists, industrialists and entrepreneurs of the society. They co-ordinated with them, arranged for the special permissions required to be given to their industrial units to open and manufacture the masks and other PPE items. Finally, the delivery of these items from the industrial units to our hospital also posed lot of administrative challenges at the various border check points during the lock down for which the permissions were arranged by the MSSOs. Through their tenacious efforts and a duty beyond the call, they managed to arrange PPE items in huge quantities. A unique requirement voiced by our security guards manning the various peripheral security check posts in the campus came to us during these times regarding the bar soaps if could be made available to them as they had an access to water but needed soaps at these posts. Without any delay, through the personal efforts of MSSO, the soaps were made available to them through donations in 24 hours time.

\section{Conclusion}

Social workers have been seen to fit into the category of employees who are valued the least because they generate no revenue, their efficiency is not readily demonstrated and their role is misunderstood or challenged. This has been attributed to various factors, including social workers' inability to articulate their value-added contributions, the hierarchy in the medical system and role blurring with other medical professionals. During this pandemic, the team of medical social service officers have contributed incredibly to serve patients, attend to their needs and given their due in the functioning of hospital in the phase of an acute crisis. It is high time that we acknowledge their pivotal role and great efforts.

\section{References}

1. Cowles LA, Lefcowitz MJ. Interdisciplinary expectations of the medical social worker in the hospital setting. Health Soc Work. 1992 Feb;17(1):57-65. doi: 10.1093/hsw/17.1.57. PMID: 1537581.[PubMed].

2. Nason F. Beyond relationship: the current challenge in clinical practice. Soc Work Health Care. 1990;14(4):9-24. doi: 10.1300/J010v14n04_03. PMID: 2237716.[PubMed].

3. Auerbach C, Mason SE, Heft Laporte H. Evidence that supports the value of social work in hospitals. Soc Work Health Care. 2007;44(4):17-32. doi: 10.1300/J010v44n04_02. PMID: 17804339.[PubMed]

4. Johns Hopkins University. COVID-19 dashboard by the Center for Systems Science and Engineering (CSSE) at Johns Hopkins University (JHU). 2020. https://coronavirus. jhu.edu/map.html (accessed July 2, 2020 


\section{Tables}

\section{TABLE 1 KEY ROLES OF MSSOS}

1. Co-ordination and implementation of Pradhan Mantri Jan Arogya Yojana (AB-PMJAY) scheme at AlIMS.

2. Facilitation of sanctioned grant under Rashtriya Arogya Nidhi (RAN) scheme to Below Poverty Line (BPL) patients for life threatening diseases.

3. Arranging financial assistance through donations received under Corporate Social Responsibility (CSR).

4. Extending help to poor patients through funds collected under poor patient fund.

5. Making free medicines and other donations available for poor and indigent patients.

6. Exemption of hospital charges for various diagnostic investigations and facilitation of railway concession for poor patients.

7. Counselling and guidance of patients in distress.

8. Rehabilitation of patients categorised under the medico-legal cases (MLC) and others unknown/unattended/ destitute/orphan under the non-MLC.

9. Facilitation of the referral of patients to private hospitals for free treatment under Economically Weaker Section (EWS) category.

10. Training and orientation of team of part time social guides..

11. Facilitation of the conversion of non-NMLC patients to MLC when mandated.

12. Rendering help to poor patients though various government schemes on the basis of their psycho-social and economic assessment.

13. Counselling services to patients by being the first point of contact when they enter the AlIMS hospital.

14. Providing accommodation facilities to outstation patients and their attendants.

15. Health promotional and educational activities through dissemination of IEC material and by organising health camps.

16. Planning and Administration: Co-ordination with the Department of Hospital Administration to improve the patient welfare activities while enabling a patient-friendly environment.

17. Looking after the medical social services of the entire hospital during critical times like epidemics, disasters and natural calamities for managing the patient care activities.

18. One Stop Centre (OSC): Co-ordination, Counselling and Advocacy for victims of Gender Based Violence.

19. Extending help and special counselling to patients with disability. 